\title{
EDUCAÇÃO E IDENTIDADE NACIONAL ARGENTINA (1884-1913)1
}

\author{
Vitor Hugo Silva Néia* \\ lattes.cnpq.br/7881249266361531
}

\begin{abstract}
Resumo: Na segunda metade do século XIX, a educação pública passou a desempenhar papel central para o fortalecimento institucional do Estado argentino e a consolidação da identidade nacional. Nesse sentido, o objetivo deste artigo é discutir a relação entre escola e nacionalidade, tendo como recorte dois temas fundamentais para a história educacional do país: a promulgação da Lei de Educação Comum, em 1884, e o projeto de educação patriótica capitaneado pelo Conselho Nacional de Educação durante a gestão de Ramos Mejía (1908-1913). Partindo da análise de seus significados e desdobramentos, pretende-se demonstrar como as políticas públicas educacionais contribuíram para selecionar e difundir os elementos mais convenientes à formação simbólica da nação, inviabilizando aspectos culturais e sujeitos sociais vistos à margem da verdadeira "argentinidade".
\end{abstract}

Palavras-chave: Educação; Argentina; Identidade nacional; História da Educação.

\section{EDUCATION AND ARGENTINIAN NATIONAL IDENTITY (1884-1913)}

Abstract: In the second half of the 19th century, public education started to play a vital role to Argentinian State institutional strengthening and national identity consolidation. This article aims to discuss relation between school and nationality, by means of two central subjects on educational history of the country: Common Education Law of 1884 and patriotic education project, headed by National Council of Education during Ramos Mejía administration (1908-1913). Based on analyses of its meanings and deployments, it seeks to demonstrate how public policies contributed to select and disseminate most convenient elements to symbolic formation of the Nation, making invisible cultural aspects and social individuals seen as apart from the truly "Argentinity".

Keywords: education; Argentina; national identity; History of Education.

\footnotetext{
${ }^{1}$ Artigo resultante de pesquisa de mestrado financiada em parte pela Coordenação de Aperfeiçoamento de Pessoal de Nível Superior (CAPES).

* Mestre em História Social pela Universidade de São Paulo, USP (Brasil). Contato: vths@hotmail.com.
} 


\section{Introdução}

A formação do Estado-nacional argentino foi um processo complexo que, desde o século XIX, envolveu distintas questões políticas, sociais, militares, jurídicas e administrativas. Ao mesmo tempo em que as instâncias burocráticas tomavam corpo, o poder do governo central era organizado e o território era unificado e pacificado, foram direcionados esforços para a construção de sentidos simbólicos para a nação que fossem estáveis, homogêneos e atendessem a um desejado modelo civilizatório, proposto pelas elites dirigentes e pelos pensadores que dela faziam parte.

Um dos mecanismos privilegiados para o fortalecimento da identidade nacional foi a educação escolar. Políticos e teóricos como Domingo Faustino Sarmiento entendiam a escola como essencial para a construção do espírito público, atributo inerente ao sistema republicano (SOARES, 2002, p. 23). Entre as iniciativas educacionais utilizadas pelos governos centrais para o fortalecimento de seu poder hegemônico e a afirmação de seus projetos para a nacionalidade, estiveram a criação de um sistema de ensino universal, laico, gratuito e obrigatório e a centralização das políticas públicas.

Por meio da discussão historiográfica e de autores do século XIX, este artigo apresentará alguns antecedentes relevantes para se pensar a formação do Estado-nacional argentino, entre os quais a imigração. Na sequência, serão detalhados os pontos da Lei n. ${ }^{0} 1.420$ de Educação Comum, promulgada em 1884, e as mudanças sociais e políticas que alteraram a visão anteriormente idealizada a respeito dos imigrantes europeus. A reflexão caminhará para a análise de outro importante texto legislativo, a Lei Láinez, de 1905, que possibilitou ao governo nacional abrir milhares de escolas no interior do país, efetivando os propósitos da Lei de Educação Comum. Finalmente, o artigo abordará o projeto de apelo patriótico concretizado pelo Conselho Nacional de Educação (CNE) na gestão de José María Ramos Mejía (1908-1913). Para isso, serão igualmente considerados os pensadores da Geração do Centenário da Independência (1910), atuan- 
tes nas políticas públicas educacionais. Entre as principais questões colocadas por esses autores, estavam a defesa das tradições nacionais e a "argentinização" dos imigrantes e de seus descendentes, em relação às quais a escola exerceria papel fundamental.

\section{A formação do Estado-nacional argentino}

A organização do primeiro governo provisório, em 25 de maio de 1810, e a declaração de emancipação pelo Congresso de Tucumán, em 9 de julho de 1816, foram os grandes marcos iniciais do longo processo de formação do Estado-nacional argentino. Grosso modo, entre 1810 e 1830, foram criados os primeiros símbolos pátrios, como o hino e a bandeira; de 1830 a 1880 acentuou-se a institucionalização do poder estatal, que passou a regular a ordem política; por fim, entre 1880 e 1930, aprofundaramse os mecanismos de consolidação da identidade nacional (ZAIDENWERG, 2013a, p. 28).

Após décadas de guerras civis e rivalidades políticas, os liberais chegaram à presidência em 1862, com Bartolomé Mitre (BETHELL, 2009, p. 667). Na sequência da vitória sobre os federalistas, partidários da autonomia das províncias, foi necessário um amplo esforço de articulação e reorganização estatal, orientado para a afirmação de um poder centralizado (OSZLAK, 1982, p. 9). À medida que o Estado se fortalecia, era preciso promover a integração do país, com diferenças profundas entre a cidade e o campo, baixa densidade demográfica no interior, existência de distintos grupos étnicos e outros fatores que, sob a ótica do liberalismo vigente, impediam a desejada homogeneização social e o consequente avanço do projeto nacional.

Conforme assumia funções antes a cargo de setores como a Igreja (entre as quais os registros de nascimento e os matrimônios), o governo central normatizava aspectos relativos à administração, à justiça e à economia (ROMERO, 2012; OSZLAK, 1982). Nesse sentido, a regulamentação do capital e das relações de produção, por exemplo, incluiu medidas tributárias, aduaneiras, monetárias e financeiras, com estímulos para a 
sustentação de alianças políticas regionais. As duas últimas décadas do século XIX foram de forte expansão econômica, atrelada à demanda internacional por gêneros primários como o trigo, a lã e a carne bovina. Investimentos estrangeiros, sobretudo britânicos, financiavam projetos de infraestrutura, especialmente as ferrovias (ROMERO, 2012), ampliando a necessidade de mão-de-obra. Ao mesmo tempo, a anexação forçada de territórios indígenas autônomos pelas campanhas militares dos anos $1870 \mathrm{e}$ 1880, conhecidas como a "Conquista do Deserto", estimulou o povoamento e a colonização das vastas e férteis planícies incorporadas à autoridade do Estado-nacional².

O Estado passou a definir políticas de fomento à vinda de europeus, com base no pensamento de liberais como Juan Bautista Alberdi, mentor da Constituição de 1853. Para ele, os imigrantes, especialmente os do Norte da Europa, eram necessários para superar o atraso argentino, associado aos habitantes do campo, sobretudo aos índios e gauchos (ALBERDI, 2011). Não se tratava, portanto, somente de atrair mão-de-obra, mas também de transformar as bases sociais e étnicas do país. Já Domingo Faustino Sarmiento, que chegou à presidência em 1868, via na imigração o potencial para desenvolver os "desertos" do interior, em sua consagrada relação dicotômica com a "civilização"3. Seu projeto de nacionalidade representava o resultado do "triunfo da cidade sobre o campo, da sociedade sobre o isolamento, da agricultura sobre a pecuária, das luzes (produto da educação) sobre as trevas" (DEVOTO, 2000, p. 35).

\footnotetext{
${ }^{2}$ Sobre a importância dos indígenas na consolidação do Estado-nacional argentino e o contexto que culminou com a Conquista do Deserto, ver: PASSETTI, 2012.

3 Como um dos principais opositores do federalismo e do rosismo e pensador próximo da Geração de 1837, Domingo Faustino Sarmiento publicou, em 1845, Facundo o civilización y barbarie en las pampas argentinas, obra-prima da literatura nacional. Partindo da biografia do caudilho Juan Facundo Quiroga, político gaucho do Partido Federalista, propôs um projeto para a nação argentina assentado na dicotomia da civilização - associada aos preceitos políticos do liberalismo e do unitarismo e às formas de convívio, cultura e sociabilidade das cidades, lugares do progresso - em oposição à barbárie, fruto do federalismo e símbolo do atraso do "deserto", imagem telúrica atrelada à vastidão das planícies do interior - terras de caudilhos, indígenas e gauchos. Essa oposição filiava-se a teorias sociais que se desenvolviam na Europa no mesmo período, muitas delas partidárias do determinismo geográfico e do evolucionismo.
} 
Entre 1880 e 1890, dos mais de um milhão de imigrantes que desembarcaram na Argentina, cerca de 650 mil radicaram-se no país, que à época contava aproximadamente com dois milhões de habitantes (ROMERO, 2012). Alguns fixaram-se no campo, mas foram muitos os que se sentiram atraídos pelas oportunidades que as cidades ofereciam. Buenos Aires e outros centros urbanos assistiram a uma rápida expansão demográfica. No total, estima-se que mais de 4,6 milhões de estrangeiros tenham emigrado para a Argentina entre 1854 e 1914, cifra inferior apenas às do Canadá e dos Estados Unidos no continente americano (SECRETARIA DA AGRICULTURA, 1950, pp. 139-140).

\section{A Lei n. 1.420 de Educação Comum}

Tanto os políticos e pensadores da Geração de 1880 quanto aqueles que os antecederam compartilhavam da firme crença na educação como o meio mais efetivo para se atingir a desejada civilização. Desde a década de 1860, ela foi assumida como o principal instrumento de consolidação do Estado-nacional, necessário para o controle e a coesão social (OSZLAK, 1997, p. 151). "A escola passou a ser (...) sustentação do progresso (...) todos os estadistas de finais do século XIX divergiam em numerosos pontos, mas tinham um elemento em comum: a necessidade de difundir a escolarização" (ZAIDENWERG, 2013a, p. 66).

Ainda durante a presidência de Sarmiento, até hoje considerado o "pai da escola" argentina, foi promulgada a Lei n. ${ }^{\circ} 463$ de Subvenções Nacionais de 1871, que determinou a criação de fundos para o financiamento e o controle da educação pública nas províncias (PUIGGRÓS, 1991, p. 77). A legislação coincidiu com o período das últimas rebeliões federalistas, colocando a formação escolar como uma preocupação politicamente estratégica para o governo central. Ela foi seguida pela Lei de Educação Comum da Província de Buenos Aires, de 1875, e pela sanção do Regulamento Geral das Escolas, de autoria da Comissão Nacional de Educação, também dirigida por Sarmiento. 
Em 1884 foi promulgada a Lei n. ${ }^{\circ} 1.420$ de Educação Comum. Criada durante a primeira presidência de Julio Argentino Roca, consolidou o sistema educacional centralizado, hierárquico, utilitário e universal, mas "altamente discriminatório e que pretendeu homogeneizar as expressões da cultura popular" (PUIGGRÓS, 1991, pp. 78-81). Por outro lado, desde a promulgação da Constituição de 1853 , as províncias haviam conseguido manter a prerrogativa de legislar sobre seus próprios sistemas educativos, de modo que a tentativa de homogeneização e controle da educação nacional ainda esbarrava nesses poderes locais (PINEAU, 2007, p. 11). Assim, à época, a jurisdição da Lei . $^{\circ} 1.420$ permaneceu limitada às escolas da cidade federalizada de Buenos Aires, dos Territórios Nacionais e de adultos.

O texto legislativo contou com a contribuição ativa do ex-presidente Sarmiento, durante sua permanência como superintendente-geral do recém-criado Conselho Nacional de Educação (CNE) e mesmo depois de seu afastamento. A Lei determinou o ensino obrigatório, gratuito, laico e progressivo, assumido como instrumento essencial ao desenvolvimento moral, intelectual e físico (ANAIS DA LEGISLAÇÃO ARGENTINA, 1884), dispôs sobre a criação de distritos escolares e de escolas públicas e definiu um currículo escolar básico, de viés pragmático, orientado para os processos de modernização, progresso e civilização perseguidos pelo Estado.

Os conteúdos curriculares passaram a incluir, além da leitura, da escrita, das ciências naturais e das operações aritméticas, a valorização do idioma nacional, preceitos de moral e urbanidade, o ensino da história e da geografia, princípios monetários e sistema de pesos e medidas, lições de higiene, conhecimentos sobre a Constituição, desenho, música, ginástica, trabalhos manuais e economia doméstica para as meninas e, para os meninos, noções militares. Para os alunos do interior, havia, também, aulas sobre fundamentos de agricultura e pecuária.

O ensino deveria ser orientado pela laicidade; a educação religiosa ficava restrita aos horários extraclasses e precisaria dar conta de variadas denominações de culto. A legislação determinou, ainda, a criação de jardins de infância, de estabelecimentos escolares para adultos "deseduca- 
dos" em lugares como fábricas, presídios e quartéis, e de escolas itinerantes nas regiões mais isoladas e com menor densidade demográfica, onde não fosse possível a construção de edifícios fixos. Todos deveriam adotar um currículo semelhante ao planificado para as escolas regulares.

Os pais e responsáveis ficavam sujeitos a sanções penais, caso fossem omissos em relação à matrícula e à frequência de seus filhos às aulas. Os castigos corporais foram proibidos. Também se incluíram regulamentações para o ensino doméstico e os estabelecimentos particulares, além da abertura das chamadas bibliotecas populares. $O$ texto legislativo instituiu, igualmente, cuidados básicos de saúde aos alunos, como a realização de inspeções médicas e de campanhas de vacinação nas escolas.

A Lei n. ${ }^{0} 1.420$ normatizou o exercício do magistério. A profissão docente foi proibida ao professor estrangeiro que não possuísse autorização nem dominasse a língua espanhola. Foram padronizados aspectos da carreira, incluindo a progressão no cargo, a formação e a aposentadoria. A boa conduta dos mestres passou a ser uma exigência legal. Finalmente, o texto dispôs sobre o financiamento da educação pública dos estabelecimentos regidos pela Lei e sobre a inspeção das escolas. Sua direção e administração ficaram subordinadas ao CNE, formado por um presidente e quatro vogais. Com isso, progressivamente, o Estado buscou centralizar e regular as relações de ensino, convertendo-as em políticas públicas.

Enquanto modelo de relevante penetração entre as elites latinoamericanas, na França oitocentista a educação também se tornava fundamental para as estratégias políticas de coesão social e assumia uma perspectiva civilizatória e moralizante, inspirada, por exemplo, pelas discussões sociológicas de Émile Durkheim (ORTIZ, 1989). O contexto francês da década de 1870, início da Terceira República, era marcado por contrastes e tensões. Em oposição à população majoritariamente rural, vista como alheia ao projeto republicano, colocava-se um ideal de país civilizado, herdeiro das Luzes. Era necessário educar as massas, associadas ao atraso do Antigo Regime e formadas por habitantes que, em parte, desconheciam a língua francesa normatizada. Para isso, empreendeu-se uma ampla reorganização do ensino primário e secundário, que deveria conduzir à integração nacional e à diluição desses conflitos. Esse "cerimonial patriótico 
escolar" seria em parte apropriado pela experiência argentina (DEVOTO, 2000, p. 50).

\section{A imigração como ameaça}

Além da Lei de Educação Comum de 1884, diversos outros dispositivos foram propostos para garantir a tão almejada homogeneização e disciplinação da população, diante do crescimento demográfico cada vez mais acentuado. Paulatinamente, as elites dirigentes, antes entusiasmadas pelo progresso associado à imigração, passou a ver o imigrante como elemento desestabilizador e como risco para a identidade nacional (ZAIDENWERG, 2013a, p. 66). A crise econômica da década de 1890 e os primeiros focos de mobilização entre os trabalhadores, "não raro com experiência sindical trazida do país de origem, penalizados pela inflação e submetidos a condições de labuta insalubres e exaustivas" (SOARES, 2002, p. 24), contribuíram para um ambiente de tensão que começava a ameaçar a estabilidade social.

Os estrangeiros e a população criolla pobre ocuparam espaços e funções sociais distintos dos pretendidos para a Buenos Aires da Belle Époque, idealizada pelo projeto liberal, aspirante a convertê-la numa capital europeia na América Latina (SARLO, 2010). Ao longo do segundo mandato presidencial de Julio Argentino Roca, na virada do século XX, o Estado aprofundou a centralização institucional e o discurso de construção do ideal de nação, dedicado a "promover a homogeneização geopolítica do país, a partir de um repertório consensual de emblemas culturais, costumes sociais e ideologias nacionais" (SOARES, 2002, p. 69). Para isso, o governo endureceu a repressão aos "perturbadores da ordem", alcunha que passou a identificar muitos imigrantes.

Além da decretação de estados de sítio, a Lei n. ${ }^{\circ} 4.144$ de Residência, promulgada em 1902 e conhecida como Lei Cané, autorizou a deportação de estrangeiros sem a necessidade de julgamento prévio (CONGRESSO NACIONAL DA ARGENTINA, 1902). Seu $2^{\circ}$ artigo previa a expulsão daqueles imigrantes cuja conduta comprometesse a segurança nacional ou 
perturbasse a ordem pública. Já em 1910, no auge da repressão contra os trabalhadores, a Lei de Defesa Social "contribuiu para proibir, sancionar, perseguir e deportar todos aqueles que a Lei de Residência de 1902 não havia conseguido" (ZAIDENWERG, 2013a, p. 69). Essas legislações representaram uma inflexão nas políticas públicas e no pensamento argentino sobre a imigração.

Importante considerar que os imigrantes e seus descendentes conformavam realidades multifacetadas em meio a distintas nacionalidades, aspirações, experiências, repertórios, limitações e habilidades. A maioria permanecia identificada pela rotina cansativa das fábricas, pelos problemas sanitários e habitacionais, pela repressão e pela perseguição policial, ainda que alguns pertencessem às elites. Aos poucos, souberam criar estratégias de ascensão, perfizeram redes de solidariedade e constituíram associações de cooperação. Além disso, principalmente durante as primeiras décadas do século XX, muitos imigrantes preservavam a "retórica nacionalista e patriótica" de seus locais de origem, o que dificultava sua assimilação (DEVOTO, 2000, p. 56-57).

\section{Educação patriótica e a Geração do Centenário}

No campo educacional, mostrava-se cada vez mais necessário reforçar a proposta nacional de universalização do ensino gratuito, obrigatório, laico e gradual, ampliando o alcance da Lei de Educação Comum, restrita às escolas de Buenos Aires, dos Territórios e de adultos. Uma importante medida nesse sentido ocorreu em 1905. Por iniciativa do senador Manuel Láinez, foi sancionada a Lei . $^{\circ} 4.878$, conhecida como Lei Láinez, que autorizou o governo federal a instalar escolas primárias nacionais de acordo com as demandas das províncias, sobretudo em áreas de baixa escolarização e com altos índices de analfabetismo (CONGRESSO NACIONAL DA ARGENTINA, 1905). 
Essa legislação fortaleceu a centralização das políticas educacionais do Estado-nacional frente aos governos locais, que administravam as escolas provinciais. Por meio do Conselho Nacional de Educação, foram abertos centenas de estabelecimentos primários, mistos, infantis e rurais em todo o país, que passaram a ser regidos pela Lei de Educação Comum, possibilitando maior controle dos currículos e das práticas educacionais. Sobretudo nas regiões mais pobres e afastadas, essas escolas rapidamente ultrapassaram em quantidade os estabelecimentos provinciais, contribuindo para a diminuição do número de analfabetos e para o aumento da escolarização. Todavia, esse movimento levou à sobreposição de sistemas de ensino distintos, ocasionando tensões entre diferentes estruturas, propostas, orçamentos, planos de salário etc. Em várias províncias, que desejavam poupar recursos, muitas escolas foram fechadas ou transferidas para a gestão do governo federal (PINEAU, 2007, p. 12).

A possibilidade de aprofundar a presença institucional do Estado em todo o território argentino através da escolarização converteu-se no cerne das reflexões do CNE e dos pensadores em torno do Ministério da Justiça e Instrução Pública. Na Argentina, a ideia de uma pedagogia cívica para a escola pública já havia sido levantada em debates anteriores, como na proposta de valorização do ensino de História que constou no projeto de reforma dos planos de estudo dos colégios nacionais, elaborado pelo ministro Filemón Posse, no final da década de 1880 (DEVOTO, 2000, p. 41). Contudo, foram iniciativas isoladas e sem aplicação prática.

Em 1908, assumiu a presidência do CNE o médico José María Ramos Mejía, especialista em estudos cerebrais e destacado pensador positivista da Geração de 1880. Sua obra e atuação à frente do órgão foram fundamentais para os rumos que a política educacional da Argentina tomou no contexto das comemorações do Centenário da Independência em 1910 e diante dos temores provocados nas elites pelo impacto da imigração crescente. Os argumentos cientificistas de Ramos Mejía, orientados por sua formação médica, partilhavam da atração exercida pelo pensamento europeu sobre outros pensadores latino-americanos, que aproximaram suas 
análises dos fenômenos sociais à perspectiva biológica, como Nina Rodrigues no Brasil, Alcides Arguedas na Bolívia e Carlos Octavio Bunge também na Argentina.

Em Las multitudes argentinas (1899), Ramos Mejía defendeu a necessidade de se converter as multidões, irracionais, primitivas e adensadas pela recente imigração em massa, em organismos governáveis e capazes de realizações. Para isso, era preciso apelar ao potencial cativante e emocional dos símbolos e não à razão, que teria pouca eficiência sobre esses setores. Nesse sentido, a educação surgia como o mecanismo mais efetivo para nacionalizar e guiar o heterogêneo povo argentino, por meio da valorização das efemérides, do patriotismo e dos heróis nacionais. Em síntese, para o progresso, a unidade e a harmonia da nação, era preciso argentinizar as fragmentadas e convulsas multidões.

À frente do CNE até 1913, as políticas empreendidas na gestão de Ramos Mejía foram fortalecidas pela abertura das escolas Láinez e por diagnósticos a respeito da situação do sistema escolar argentino. A partir de 1908, ele deu impulso a um verdadeiro projeto de educação patriótica, detalhadamente sistematizado para promover a difusão dos valores nacionais através do país, efetivando e aprofundando as motivações por detrás da Lei de Educação Comum. O Estado-nacional necessitava internalizar uma identidade coletiva por meio de símbolos que reforçassem noções de solidariedade e pertencimento (OSZLAK, 1997, p. 13). Com Ramos Mejía, esses esforços foram direcionados para uma ação efetiva de transmissão do "espírito e da moral republicana e patriótica" que, com base no pensamento positivista, aproximou o patriotismo a uma verdadeira religião, motivando seu culto (ZAIDENWERG, 2013c, p. 239).

A ascensão de Ramos Mejía como presidente do Conselho Nacional de Educação (...) foi um marco na elaboração de uma sólida e homogênea educação moral e uma ampla instrução acentuadamente nacional. Ele resolveu instaurar um modelo de educação patriótica que impregnaria tudo, desde os planos das diferentes disciplinas, a conduta no espaço escolar e fora dele, até os livros de texto ou manuais escolares, dando assim um impulso especial e renovado à formação nacionalizadora. (ZAIDENWERG, 2013c, p. 239). 
As aulas deveriam exaltar os símbolos da nação. Em Leitura e Escrita, o estudo do idioma castelhano tornou-se um dos principais motores de afirmação da argentinidade e de coesão social. Não apenas o uso da língua em si, mas os conteúdos voltaram-se às temáticas relacionadas à pátria. Além das obras dos autores nacionais, buscou-se, por exemplo, incluir nos ditados, conversações e leituras assuntos de caráter patriótico, como o hino nacional, biografias e frases de personagens históricos (ZAIDENWERG, 2013c, p. 240). Combatia-se, também, o uso dos estrangeirismos e de outros idiomas, comumente falados pelos filhos dos imigrantes em casa (ZAIDENWERG, 2013b, p. 82).

A História e a Geografia foram consideradas fundamentais para a afirmação dos sentimentos nacionais. Nas aulas de História, procurou-se construir uma narrativa homogênea sobre o passado do país, valorizando os feitos de grandes figuras, em especial dos próceres ou "pais da pátria", e utilizando-os como exemplos de virtudes e de heroísmo. Além disso, esse exercício passou pela revitalização da "cultura hispânica, da indígena ou da criolla (...) ou das três [antes rechaçadas pelo liberalismo oitocentista], numa chave de contraposição ao papel civilizador proeminente dos imigrantes europeus das construções intelectuais” do século XIX (DEVOTO, 2000, p. 50).

Já a Geografia deveria abordar não apenas os distintos lugares e paisagens que formavam as belezas naturais do país, mas também os fatos históricos ocorridos em cada um deles (ZAIDENWERG, 2013c, p. 240). As características regionais eram valorizadas, uma vez que o espaço desempenhava importância fundamental para uma nação formada por milhões de habitantes de origem estrangeira, onde a nacionalidade era associada ao direito sui solis, isto é, reconhecida àqueles que nasceram no território. Não por acaso, as escolas poderiam adaptar, com muitas restrições, algumas recomendações feitas pelo $\mathrm{CNE}$, de acordo com a realidade local (ZAIDENWERG, 2013b, p. 87).

Outra disciplina essencial para a valorização da identidade nacional era a de Moral e Instrução Cívica, que preparava os alunos para honrar e servir à pátria. Para isso, elencavam-se virtudes e comportamentos desejáveis à vida em sociedade e à formação de "um bom pai, bom cidadão e 
bom homem" (ZAIDENWERG, 2013c, p. 240). Combinadas à História, as aulas de Instrução Cívica contribuíam para o "doutrinamento patriótico" gradual, que incluía desde as ideias de sociedade, família, governo e suas instituições até os conceitos de pátria e patriotismo (ZAIDENWERG, 2013b, p. 82).

Além dessas quatro áreas de ensino, (Linguagem, História, Geografia e Moral e Instrução Cívica), às demais disciplinas era recomendado, sempre que possível, que perpassassem alguns elementos alusivos à nacionalidade em seus planos curriculares. Em aritmética, os problemas matemáticos poderiam abarcar questões sobre os impostos e sua importância para a coletividade, por exemplo (ZAIDENWERG, 2013c, p. 241).

Não somente a escolarização formal foi assumida pelo projeto de educação patriótica como um instrumento de "argentinização" das massas. Outro importante mecanismo sistematizado por meio das instruções do CNE foi a comemoração de festas e efemérides, ocasiões para reverenciar os símbolos, imagens, monumentos, heróis e feitos históricos desejáveis para a consolidação da nação. Datas como o 25 de maio e 9 de julho, associadas à Independência, tornaram-se propícias para a celebração patriótica, exaltando os mitos de origem e legitimando o projeto do Estado, principalmente depois das grandes comemorações do Centenário da Revolução de Maio em 1910.

Nessas cerimônias, as escolas continuaram a ser o âmbito privilegiado para o fortalecimento da identidade nacional, de modo que se procurou regular os procedimentos, iniciativas e mesmo os gestos e posturas pretendidos para os estabelecimentos escolares, por meio da veiculação de programas e instruções específicos para essas finalidades. Sob a condução de diretores e docentes, buscava-se envolver toda a comunidade nas festas cívicas, mobilizando vizinhos, autoridades, imprensa e as famílias dos alunos, formadas por grandes contingentes de imigrantes (ZAIDENWERG, 2014, pp. 7-8). Tratava-se, em última análise, de consolidar verdadeiras "tradições inventadas", por intermédio de atos cívicos organizados nas escolas, mas também em praças, prédios do governo, igrejas e outros espaços públicos. Elas deveriam promover, conforme Hobsbawm, a coesão social, legitimar as instituições e relações de autoridade, proporcionar momentos 
de socialização e infundir valores, comportamentos e crenças (HOBSBAWM apud ZAIDENWERG, 2013c).

Na conjuntura dos preparativos para as celebrações do Centenário da Independência, José María Ramos Mejía publicou La Escuela Argentina en el Centenario (1909), que exaltava a vocação da escola como "o gérmen da alma nacional", associada à "rememoração das tradições gloriosas nas quais se encontram as forças impulsoras da República” (RAMOS MEJÍA, 1909, p. 3). Na publicação, a função da educação nacional foi sistematizada na forma de uma série de iniciativas, sugestões e projetos, incluindo a construção de um monumento e de um museu histórico escolar, a realização de festivais e exposições, a organização de conferências, concursos, resenhas e monografias, entre outras atividades de caráter semelhante.

O propósito desses esforços era "convergir todas as energias para a grandeza da pátria" e "impulsionar os povos pela senda da justiça, da glória e da liberdade”. Não por acaso, os recursos complementares utilizados no cotidiano escolar deveriam despertar o interesse e a emoção nos alunos. Para isso, recomendava-se, quando possível, o uso de desenhos, quadros, retratos, projeções de luz e dramatizações, o que corroborava as proposições feitas por Mejía em Las multitudes argentinas, segundo as quais as massas deveriam ser educadas pela emoção, mais do que pela razão.

Na mesma época, o presidente do CNE solicitou a um de seus colaboradores, o técnico Juan Pedro Ramos, a realização de um estudo sobre o estado da educação no país. Ele deu origem à Historia de la Instrucción Primaria en la República Argentina, 1810-1910, que destacou as consequências negativas do fenômeno da imigração sobre o caráter nacional e levou, inclusive, à proibição do popular romance Corazón nos estabelecimentos escolares, uma vez que essa obra foi acusada de fomentar "sentimentos em relação a outras pátrias" (SOARES, 2015, p. 430). Assim, a visão da imigração e do cosmopolitismo como riscos à unidade e à estabilidade nacionais ganhava cada vez mais força entre aqueles que direcionavam as políticas públicas do Conselho.

O grupo de intelectuais relacionados às comemorações oficiais do Centenário da Independência e ao projeto de viés patriótico do CNE foi 
denominado pela historiografia e pela crítica literária como a Geração do Centenário. À sua doutrina deu-se o nome de nacionalismo, justamente pelas preocupações em comum a respeito do que deveria conformar a nacionalidade argentina, principalmente por meio de atributos culturais associados a um conjunto de tradições eleitas como autênticas e nacionais. Essa vertente do nacionalismo concorria com outras correntes filosóficas e políticas que também debatiam a nacionalidade, muitas delas sob perspectivas distintas e até antagônicas. Esses movimentos ganhariam força com a Primeira Guerra Mundial (1914-1918), que provocou uma crise de paradigmas e de consciência por toda a América Latina, antes orientada por modelos europeus de civilização e progresso (COMPAGNON, 2014).

Ainda que divergissem em alguns pontos, os autores da Geração do Centenário partilhavam da crítica ao cosmopolitismo, visto como a causa da iminente desintegração social e da perda da identidade nacional, e reivindicavam o resgate da "verdadeira" alma argentina. Entre seus representantes, destacaram-se Manuel Gálvez, Ricardo Rojas e Leopoldo Lugones (BEIRED, 1999). Em geral, os teorizadores concordavam que a valorização das tradições nacionais permitiria a reconstrução da estabilidade social. Outro ponto em comum era a crítica feroz à imigração. Houve mesmo quem defendesse a necessidade de militarização do país. Alguns idealizavam a herança espanhola e reivindicavam sua restauração, em continuidade com as tradições argentinas, dentro daquilo que se denominou hispanismo. Também as tradições gauchescas, criticadas por autores oitocentistas como Sarmiento, passaram a ser valorizadas por sua originalidade regional, o que motivaria o interesse crescente pelo folclore nos anos posteriores.

Parte dessas ideias foi assumida e instrumentalizada pelos organismos do Estado-nacional. Pela educação escolar e a afirmação dos valores pátrios, os nacionalistas do Centenário objetivavam integrar a população criolla, indígena e imigrante a um projeto de nação coeso e pouco aberto à contestação. Participando das instâncias decisórias do CNE, esses pensadores tiveram ascendência nos rumos das políticas públicas educacionais, elaborando relatórios, pareceres e outras publicações para o Conselho. Algumas de suas posições ganharam contornos políticos nas décadas 
de 1920 e, em especial, de 1930, quando um golpe militar pôs fim ao segundo mandato presidencial de Hipolito Yrigoyen, da União Cívica Radical, iniciando a chamada "Década Infame".

\section{Considerações finais}

Na segunda metade do século XIX, a educação pública passou a desempenhar papel primordial para a centralização institucional do Estado argentino e a consolidação da identidade nacional. O pensamento liberal tinha entre seus principais eixos condutores o progresso material, urbano e tecnológico e o fortalecimento das instituições públicas, especialmente a escola, entendida como essencial para a conformação de um modelo de civilização e cidadania e para a construção orientada da nacionalidade.

A Lei de Educação Comum, de 1884, foi a primeira grande iniciativa de universalização do ensino público, laico e gratuito, servindo de inspiração para outros países da América Latina. À medida que os imigrantes passavam a ser vistos como uma ameaça à ordem social, da mesma forma que os indígenas e os gauchos no século XIX, a retórica patriótica aprofundouse nos currículos escolares, planos de aula, materiais didáticos e festas cívicas. Para isso, o governo nacional abriu milhares de escolas e expandiu sua jurisdição, em consonância com a Lei Láinez de 1905, e desenvolveu um minucioso projeto educacional, impulsionado pelo médico José María Ramos Mejía e por pensadores e técnicos identificados à Geração do Centenário.

Em última análise, as reflexões envolvendo a educação e o Estado argentino, entre as décadas de 1880 e 1910, demonstraram como as políticas públicas educacionais foram fortalecidas, ampliadas e ressignificadas para a promoção e manutenção de práticas hegemônicas, que sustentavam a ordem estabelecida e, no que se refere à consolidação da identidade nacional, atuavam para selecionar e difundir os valores e símbolos mais convenientes à formação simbólica da nação, inviabilizando aspectos culturais e sujeitos sociais vistos à margem da verdadeira "argentinidade". 
Importante frisar que, entre o planejado e o executado pelo CNE, havia uma série de nuances e desvios. Em localidades menos povoadas e mais afastadas dos centros urbanos, como o Território Nacional do Río Negro, por exemplo, a realidade do sistema de ensino era marcada pela dificuldade de se atrair e formar professores, pela precariedade física dos prédios escolares, pela concorrência com as congregações religiosas, por altas taxas de evasão e pelas grandes distâncias entre as escolas e as propriedades rurais onde muitos alunos viviam, entre outros fatores que evidenciavam os limites e desafios enfrentados pelo Estado-nacional na prática (GARCÍA \& TEOBALDO, 1993).

\section{Referências}

ALBERDI, J. B. Bases y puntos de partida para la organización política de la República de Argentina. Fundação Biblioteca Virtual Miguel de Cervantes, 2011.

ANAIS DA LEGISLAÇÃO ARGENTINA. Lei de Educação Comum. Disponível em: <http://www.bnm.me.gov.ar/giga1/normas/5421.pdf>. Acesso em: $10 / 1 / 2017$.

BEIRED, J. L. B. Sob o signo da nova ordem: intelectuais autoritários no Brasil e na Argentina. São Paulo: Edições Loyola, 1999.

BETHELL, L. (org.). História da América Latina (volume III): da Independência a 1870. São Paulo: Edusp; Brasília: Fundação Alexandre de Gusmão, 2009.

COMPAGNON, O. O adeus à Europa: a América Latina e a Grande Guerra (Argentina e Brasil, 1914-1939). Rio de Janeiro: Rocco, 2014.

CONGRESSO NACIONAL DA ARGENTINA. Lei n. ${ }^{\circ} 4.144$ de Residência de 22 de novembro de 1902. . Lei n. ${ }^{\circ} 4.878$ de 17 de outubro de 1905.

CONSELHO NACIONAL DE EDUCAÇÃO. Cincuentenario de la Ley 1420, 1938. 
DEVOTO, F. J. Imigração europeia e identidade nacional nas imagens das elites argentinas (1850-1914). In: FAUSTO, B. (org.). Fazer a América: a imigração em massa para a América Latina. São Paulo: EDUSP, 2000.

GARCÍA, A. B.; TEOBALDO, M. Estado y sociedad civil en la conformación y desarrollo del sistema educativo en el territorio nacional de Río Negro (1884-1945). In: PUIGGRÓS, A. (org.). La Educación en las Provincias y Territorios Nacionales (1885-1945). Buenos Aires: Galerna, 1993.

ORTIZ, R. Durkheim: Arquiteto e Herói Fundador. Revista Brasileira de Ciências Sociais, v. 4, n. 11, Rio de Janeiro, outubro de 1989.

OSZLAK, O. Reflexiones sobre la formación del estado y la construcción de la sociedad argentina. Desarrollo Económico Revista de Ciencias Sociales, vol. XXI, 1982, Janeiro-Março: Buenos Aires, Argentina.

. La formación del Estado argentino: orden, progreso y organización social. Buenos Aires: Planeta Argentina, 1997.

PASSETTI, G. Indígenas e criollos: política, guerra e traição nas lutas no sul da Argentina (1852-1885). São Paulo: Alameda, 2012.

PINEAU, P. (org.). A cién años de la Ley Láinez. Buenos Aires: Ministerio de Educación, Ciencia y Tecnología, 2007.

PUIGGRÓS, A. (org.). Historia de la educación argentina: Sociedad civil y estado en los orígenes del sistema educativo argentino. Buenos Aires: Editorial Galerna, 1991.

RAMOS MEJÍA, J. M. Las multitudes argentinas. Barcelona: Linkgua Digital, 2014.

. La Escuela Argentina en el Centenario. Buenos Aires: Conselho Nacional de Educação, 1909.

ROMERO, L. A. Breve história contemporânea da Argentina. Buenos Aires: Fondo de Cultura Económica, 2012. (e-book).

SARLO, B. Modernidade periférica: Buenos Aires, 1920 e 1930. São Paulo: Cosac Naify, 2010.

SECRETARIA DA AGRICULTURA, INDÚSTRIA E COMÉRCIO. Boletim do Departamento de Imigração e Colonização. São Paulo, n. ${ }^{\circ}$ 5, dezembro de 1950.

SOARES, G. P. A Semear horizontes. Tese de doutorado (História Social). Universidade de São Paulo, São Paulo, 2002.

. Monteiro Lobato, Juan P. Ramos e o papel dos inquéritos folclóricos na formação cultural e política da nação. Varia Historia, Belo Horizonte, v. 31, n. 56, 2015.

ZAIDENWERG, C. La 'argentinización' de los Territorios Nacionales a través de la educación formal e informal: Estudio de caso Río Negro 
(1908-1930). Tese de Doutorado (História). Universitat de Barcelona: Barcelona, 2013.

. Amar, honrar y servir la Patria. La escuelas del Territorio Rionegrino y su aporte a la obra argentinizadora en el Sur (1908-1930). Páginas - Revista Digital de la Escuela de Historia. Ano 5, n. 9, Rosário, 2013. . Un proyecto 'argentinizador'. Educación y efemérides en la región patagónica y rionegrina. História Unisinos. v. 17, n. 3, p. 237-247, 2013. - Celebrando la patria en la gobernación norpatagónica de Río Negro (1908-1930). Naveg@mérica, Revista Electrónica de la Asociación Española de Americanistas, n. 12, 2014.

Recebido em 18 de janeiro de 2017. Aprovado em 15 de abril de 2017. 